\title{
Papers
}

\section{Do trees really cause so much damage to property?}

Received (in revised form): 19th March, 2008

\section{Christopher Overbeke}

graduated with a 2:1 in Modern History from the University of London in 1986. After working with a large American company of architects and structural engineers for several years he pursued a career in horticulture and gained a distinction in the Advanced National Certificate in Commercial Horticulture. This evolved into a career in arboriculture. He worked in local government before gaining an MSc in Arboriculture from the University of Aberdeen. He worked in arboricultural consultancy before setting up OMC Associates. He also works 1-2 days a week for a London local planning authority.

Correspondence: Christopher Overbeke, OMC Associates, 28 Shelford Road, Cambridge CB2 9NA, UK; Tel: +44 1223 842254; Fax: +441223 846870; E-mail: info@omc-associates.co.uk

\begin{abstract}
Whether a tree is causing direct damage to a property is generally obvious. Whether a tree is bearing or will bear any indirect influence on a property is far less clear but dependent on three fundamentals: (1) whether roots are under or can get under foundations, (2) the capacity of those roots to abstract moisture and crucially (3) whether the foundations bear upon a shrinkable substrate. In trying to determine factors 1 and 2, too much emphasis is placed on attributing a tree with a certain moisture uptake capacity and little if none is placed on considering other criteria that are fundamental in influencing these two processes. These are explored in greater detail in this paper and all must be considered holistically. Trees can cause damage to buildings and this can be significant but this must be clearly established and once established the invariably cheaper option of tree management to a structural solution must be challenged where appropriate in an environment where sustainable development is becoming crucial and the benefits of greenery in urban spaces is increasingly recognised.
\end{abstract}

Journal of Building Appraisal (2008) 3, 247-258. doi:10.1057/jba.2008.6

\section{Keywords:}

trees, foundation, indirect damage, direct damage, soil moisture content, moisture demand capacity

\section{INTRODUCTION}

Only when a tree is nearing maturity is its landscape value maximised, when they become valuable and irreplaceable features, particularly in built up areas. We are losing a significant proportion of trees because of alleged association with structural damage or concern about future possible structural damage. This paper aims to highlight some of the flaws on which these assessments may be made and discuss the variables that should be considered when assessing a tree's potential role in direct and indirect damage to a property with particular emphasis on indirect damage. Although an arboriculturist is best qualified to make such a judgment, other property professionals can make more thoughtful decisions based on some of the considerations raised in this paper. 
Table I: NHBC classification of water demand for genera

\begin{tabular}{lll}
\hline High water demand & Moderate water demand & Low water demand \\
\hline Broad-leafed genera & & \\
Elm & All other genera & Beech \\
Eucalyptus & & Birch \\
Oak & & Holly \\
Poplar & & Magnolia \\
Willow & & \\
Coniferous genera & Alberry \\
Cypress & others & \\
\hline
\end{tabular}

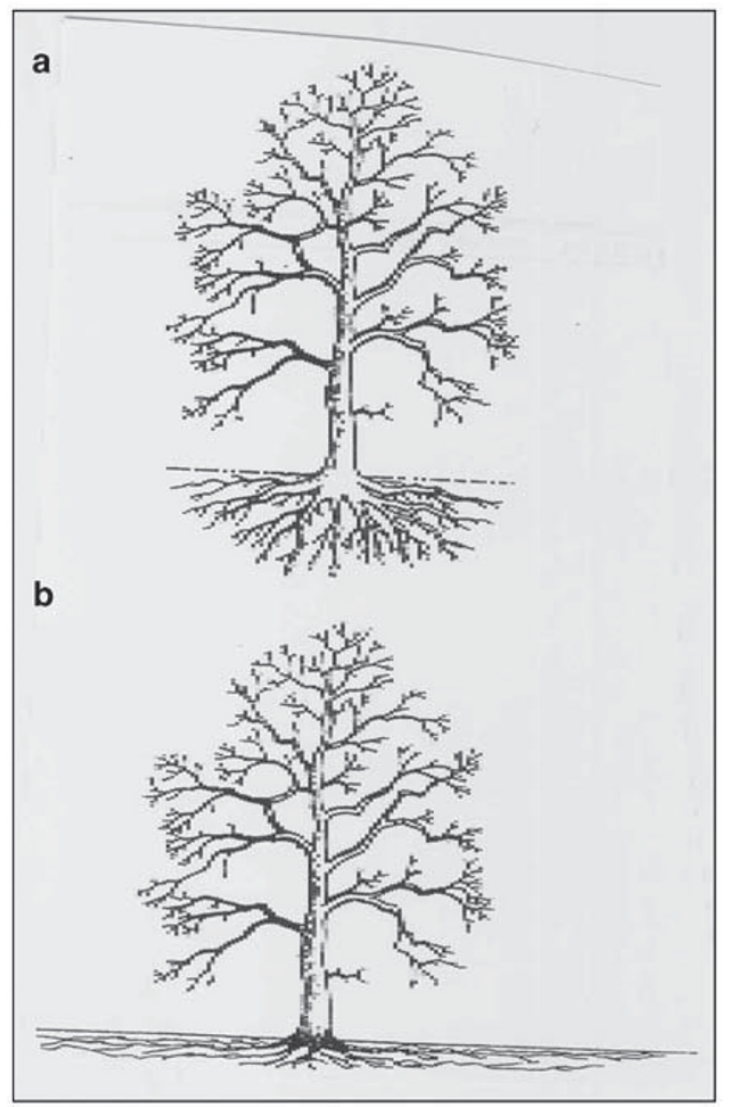

Figure I: Popular conception (a) and realistic representation (b) of tree root systems (Helliwell, D.R., 1989)

The NHBC has attempted to attribute trees with certain moisture uptake capacities in order to determine appropriate foundation depths. This and the tables of appropriate distances between trees and property used by the ISE and the Loss Prevention Council are based on P.G. Biddle's water demand classification of tree species (Table 1).

All species of trees are categorised as, 'high', 'moderate' or 'low' water demanders. Species in the high group are generally considered to extend their influence on soil moisture levels over a distance of 125 per cent the height of the tree. Moderate water demanders extend their influence over 75 per cent of their height and low water demanders extend their influence over 50 per cent of their height. 
This is too simplistic to be an accurate tool to assess a tree's potential to affect a property. As Dr Biddle points out, 'the amount of suction exerted by all species of trees in a temperate climate is similar and so the potential of a tree root to affect a property is largely determined by site factors'. These factors need to be carefully explored and can be categorised as arboricultural characteristics, site conditions and structural features (Figure 1).

\section{INDIRECT AND DIRECT DAMAGE OR POTENTIAL DAMAGE}

Direct damage is damage caused by the mechanical action of any part of a tree in direct contact with part of a structure.

This contact may be constant such as a stem of a tree abutting a wall or fleeting, such as a branch hitting a structure as it moves in wind or as it falls. It is rare for the latter to be serious and is usually avoidable by light trimming back. The former is rare simply because trees are seldom allowed to develop and mature when in contact with a structure (other than boundaries walls).

Roots encountering a solid object will divert and follow the course of least resistance, thereby causing no damage. The continuous radial expansion of trunks and structural roots in contact with a structure and in a restricted space, however, may exert sufficient pressure to displace heavy structures.

Indirect damage is caused by the influence of a tree on soil moisture levels of a substrate prone to shrinkage and expansion. The ground is de-hydrated through the transpiration of leaves abstracting moisture from the ground and, less significantly, by the interception of rainfall by the crown. The ground contracts and settlement occurs. Usually winter rainfall results in full recovery so that the process is seasonal. Conversely, removal of a tree results in long-term recovery and expansion of the ground.

\section{ARBORICULTURAL FACTORS THAT DETERMINE THE LIKELIHOOD OF TREE-RELATED DAMAGE}

\section{Variation among tree species}

Identifying a tree accurately is fundamental to the assessment of its moisture or potential moisture uptake capacity. Currently most data and reference tables refer simply to genus such as 'Willow'. This does not account for the huge variation of species within a genus. There are, for example, over 2,000 species within the pine family and these will vary dramatically in terms of size and ability to grow in a given situation. Reference to 'willow' or 'cherry', therefore, is meaningless without qualification.

Similarly, where a species or genus is referred to it often takes no account of cultivars within that species. A Lawson cypress cultivar may be referred to as 'cypress'. Notwithstanding the fact that we do not even know what species of cypress it is, it fails to account for the fact that there are hundreds of Lawson cypress cultivars with a huge variance in potential size. 'Pembury Blue' may not get much taller than $3 \mathrm{~m}$ while 'Triumph of Boskoop' can exceed $25 \mathrm{~m}$.

Conclusions about the appropriateness of one will be dramatically different from the appropriateness of another.

\section{Intra-specific differentials}

Differences between two species are little known and rarely accounted for. There can be numerous different genetic clones of a species of tree. Despite being nominally the same 
tree, two say common horse chestnuts may have quite different physiological processes and, therefore, rates and patterns of moisture uptake. This is demonstrated by P.G. Biddle in a case cited in his book 'Tree Root Damage to Buildings' (1998) where there are considerable fluctuations in soil moisture deficit at $1 \mathrm{~m}$ depth between four similarly sized horse chestnuts growing in London clay. This may explain (as may other factors) why a mature tree growing close to a building founded on clay that would normally be expected to have caused damage has never caused damage.

\section{The implications of grafting}

Many trees are grafted onto a rootstock and it is that rootstock and not the scion that will determine rates of growth and moisture uptake. This is clearly illustrated where scions taken from the same apple tree and grafted onto numerous different rootstocks determine whether a tree grows ultimately to $2 \mathrm{~m} \times 0.5 \mathrm{~m}$ or $9 \mathrm{~m} \times 9 \mathrm{~m}$.

\section{Vitality in relation to moisture abstraction capacity}

This term describes how vigorous a particular tree is, as opposed to the species in general and is one of the key determinants of a tree's ability to cause indirect damage. Sycamore, for example, is a vigorous species but a particular sycamore specimen may be old, suppressed, growing in an inappropriate location or diseased and lack vitality. Trees of poor vitality, regardless of NHBC 'water demand' classification or the vigour of the species, may be having very little influence on soil moisture levels.

Trees of the same clonal origin (ie genetically identical), for example, will show quite different patterns of soil drying on different sites because of differing environmental factors influencing a tree's growth pattern and growth rate. Such phenotypic variation is an indication of a tree's vitality. A silver birch may thrive in an open well-drained site but the identical clone will struggle and show very different growth patterns in a poorly drained shadier site.

A building near a large old tree may show signs of historic cracking but none of current movement, indicating a tree's declining vitality as it ages.

Assessment of a tree's crown is far more important in determining vitality than its height and current formulas that consider tree height in determining root zones of influence may be misleading.

\section{Competition in relation to moisture abstraction capacity}

Groups of trees do not necessarily bear more influence on a property than single trees. Trees growing in close proximity to one another have to share the same resources (not necessarily equally) and they are likely to adapt growth rates in order to survive on reduced resources. Thus a group of trees may have spindly, etiolated crowns and insignificant moisture abstraction capacity.

\section{Evergreen and deciduous}

Trees dehydrate the ground by abstracting moisture at a rate determined by their TLA (Total Leaf Area) through transpiration. Trees will aggravate the de-hydration process through the interception of rainfall. It is estimated that about a quarter of rainfall is intercepted by the crown and a third of that evaporates in the tree (Binns, 1980).

Clearly this is greater with densely foliate and evergreen species. 


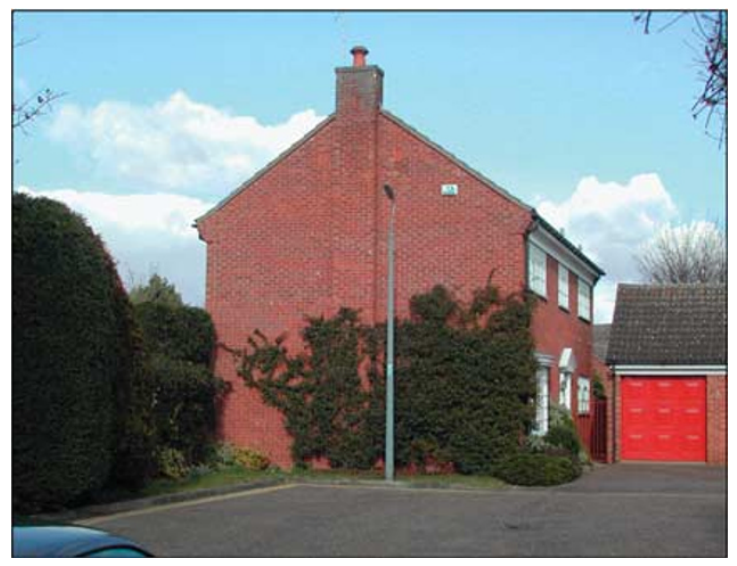

Figure 2: Seasonal fluctuations in SMD at $1.0 \mathrm{~m}$ for three horse chestnuts on similar clay (P.G. Biddle, 'Tree Root Damage to Buildings', 1998)

\section{Shrubs}

Shrubs are often overlooked because they are not trees. Notwithstanding the rather dubious distinction between a tree and a shrub (essentially they have similar patterns of root development though not so extensive), many can grow into formidable plants as large as many small trees. Elderberry, buddleja, cotoneaster, laurel, pyracantha, ivy, wisteria are just a few examples of commonly grown shrubs that can grow extremely large (Figure 2).

They are significant, not simply because of potential moisture abstraction capacity but because of characteristics associated with shrubs:

- They are often grown adjacent walls and buildings. Severe localised drying can occur and close proximity renders root trespass upon foundations more likely.

- Shrubs are commonly grown together or close to one another and develop into clusters of very dense foliage cover. Ground below evergreen shrubs can often be highly desiccated.

- Because shrubs are regarded as somewhat innocuous they are routinely allowed to grow into significant specimens.

Before decisions are made about the presence of a tree, therefore, it may be more appropriate to consider the effect of nearby shrubs. The extent of pruning regarded as effective in abating any root influence that is often inappropriate for trees can be carried out on most species of shrubs. Transplantation or containerisation can be alternative solutions.

\section{RELEVANT SITE FACTORS}

\section{Soil type}

Soils are highly relevant since vegetation cannot cause indirect damage to a property unless it bears upon a substrate that has potential for volumetric change. This is usually clay though peat is also shrinkable. The degree of shrinkability is relevant in determining an appropriate course of action. A root system abstracting soil moisture is likely to have 
rather less impact on the volume of a founding clay substrate with a P.I. of 15 per cent than that of a clay with a P.I. of 60 per cent.

Degrees of plasticity were simplified by the NHBC in 1985 into three categories and this was further refined in BRE Digest 240 in 1993 to add a category of 'Very High' for a P.I. in excess of 60 per cent (Table 2).

\section{Soil structure}

Soil structure is fundamental when making a reasoned assessment of how far a tree's roots may have extended. Root growth generally requires oxygen levels in excess of 15 per cent. Optimum oxygen levels, however, are rare and damage to the soil structure through compaction, particularly in clay soil, inhibits oxygen diffusion. Compaction plays a further role through mechanically impeding root penetration. In fine soils such as clay, bulk density can be sufficiently high to result in a cessation of root extension.

An understanding of the ground conditions of a site should, therefore, suggest to the trained eye whether tree roots have extended as far, further or less than the normally expected root spread of a given species at a given stage of growth.

On sites where bands of a more aerobic substrate such as hardcore, stone, sand, gravel, etc occur within a clay, it is reasonable to assume that this would facilitate root extension along these channels. Similarly, roots commonly follow cracks and crevices in the soil, including pipelines (though this may be also related to them exploiting the condensation on a pipe or additional soil moisture if leaks are present).

\section{Soil moisture content}

Root's search for water is fundamental in determining the scope of its root system and is the major factor that limits tree growth. Reduced moisture levels encourage roots to grow in search of water but the common perception that roots find water is erroneous. They are opportunistic and if they happen across water they will proliferate. Hence leaking drains, condensation along underground pipes, natural aquifers may all result in greater root presence in that area (Figure 3).

Many subsidence investigations involve damaged drains and, notwithstanding settlement associated with compaction of soil particles, the increased soil moisture content may have encouraged greater or a root presence that would not normally have been the case.

Saturated soils will inhibit root growth but trees have very different tolerances to flooding and though condition of the tree is relevant, the inherent differences between species to tolerate flooding must be considered. Some species such as Taxodium or Salix can survive flooding for several months or even permanently. Thus saturated soils may not be a reason to dismiss root trespass upon a property.

\section{Site history}

Knowledge of what may have occurred in the past may be a useful indicator of soil and structure dynamics.

Sites cleared of vegetation may be resulting in gradual re-hydration and swelling of the ground. Such awareness may encourage professionals investigating movement to consider heave rather than subsidence as a cause of movement with clearly very different solutions. Wrong diagnosis may exacerbate the problem by suggesting vegetation removal.

Knowledge of site history would have assisted an investigation into cracking to a 1950s bungalow that was isolated by a huge housing development. Notwithstanding the possible effects of vibration from the pile drivers, the stream bordering the garden had completely 
Table 2: Four categories of plasticity as defined in BRE Digest 240, 1993

\begin{tabular}{ll}
\hline Plasticity index (\%) & Shrinkage potential \\
\hline $10-20$ & Low \\
$20-40$ & Intermediate \\
$40-60$ & High \\
$60+$ & Very high \\
\hline
\end{tabular}

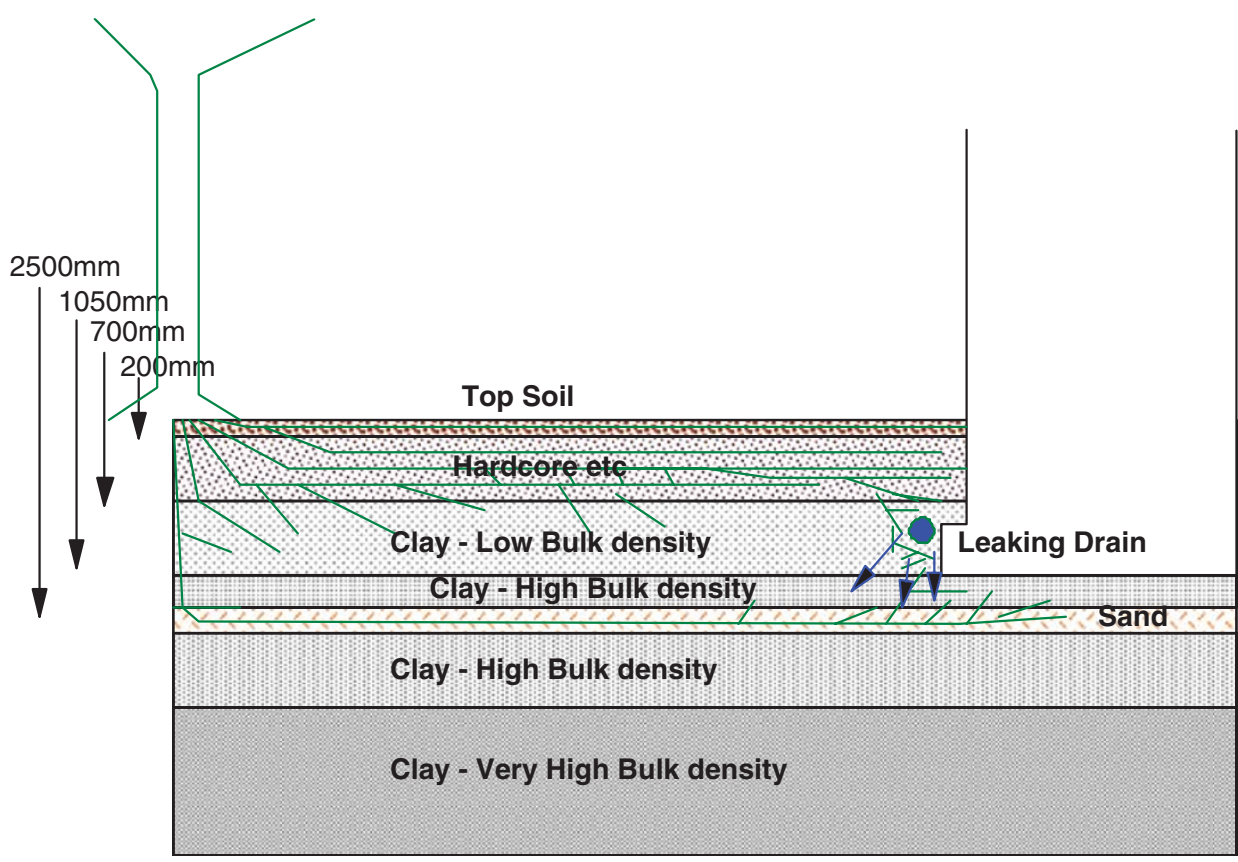

Figure 3: Large pyracantha shrub growing against wall

dried out for the first time in 40 years. It was clear that underground watercourses and ground levels had been changed dramatically resulting in this dehydration. The trees had co-existed with the property for many decades and were, furthermore, in decline. Their role in the cracking to the property was not a credible explanation but the trees were removed.

\section{Grass}

Lawns abutting damaged property may be a causal factor of subsidence. Grass is evergreen and starts transpiring much earlier than deciduous trees. It can create soil moisture deficits to $0.5 \mathrm{~m}$ by early summer through the dual process of rainfall being intercepted by a dense network of roots and significant levels of moisture abstraction.

Lawns compete fiercely with trees and research has shown tree root density to be 113 per cent more in bare soil than in grassed areas (Watson, 1988). Herbicides are, furthermore, regularly applied to lawns and this will further discourage tree roots if persistent or residual.

Since depth of drying can extend to $1.2 \mathrm{~m}$ by late summer, it is reasonable to assume that this process could be pertinent, particularly where footings are rather less. 


\section{Hardstanding}

The implications of hardstanding must be considered as part of the holistic approach to problem solving and tree involvement. Whether hardstanding is permeable or impermeable and when it was laid is relevant. An impermeable surface will greatly reduce or prevent natural recharge and may be the reason why the ground has become dry. It can reduce evaporation from the soil surface but foundations are usually significantly deeper than the level affected by evaporation. If roots manage to encroach upon an impermeable surface, moisture is removed without being replaced and a persistent soil moisture deficit may occur.

Impermeable hardstanding does, however, create an extremely hostile rooting environment and careful assessment of hardstanding should include its role in deterring root extension near a property.

Porous, level surfaces, on the other hand, allow the penetration of rain as well as reduce surface evaporation and may result in environments conducive to root growth.

\section{RELEVANT STRUCTURAL FACTORS}

\section{Foundations}

Foundation detail is critical in preventing root-related damage. BRE Guidelines are more sophisticated than in the past in so far as plasticity of the clay — albeit crudely — species — also crudely — and distance of tree is considered. Flawed as it, if these guidelines were fully enforced there would be significantly less incidence of tree-related damage.

Many structures, however, are built without Building Control approval or are exempt from its requirements (Table 3). These can be poorly constructed structures and they represent a significant percentage of investigations where trees are implicated in structural damage.

Poorly founded structures, moreover, may be vulnerable to volumetric changes of the clay regardless of the presence of trees. Thus cutting down a tree may simply achieve a reduced magnitude in seasonal movement but the movement continues. Rebuilding (often extremely poor structures) or underpinning does not necessarily need to be a significantly more expensive option to simply removing often very fine trees and is clearly a far more satisfactory and sustainable solution (Table 3).

\section{Drains}

Perhaps the most widespread problem caused by tree roots is the penetration and clogging of drains and sewers. The conditions within are perfect for root growth and roots proliferate, slowing flow rates and ultimately blocking the drains. One willow root taken from a storm sewer in Utah was $41 \mathrm{~m}$ long (Biddle, 1998).

This, however, must not be a reason to remove trees. In view of the dense network of underground pipes and roots, it is physically impossible and clearly unacceptable to remove every tree with a potential of ingress into pipes since this would result in the felling of every mature tree in an urban environment.

Roots cause damage only once they have gained ingress to drains. They rarely enter a pipe unless it is already damaged or sufficiently deteriorated. Where trees are present drains should be periodically inspected and, where roots have gained entry, re-lined or replaced with UPVC pipes so that roots cannot penetrate in the future. Simply clearing them of roots periodically is an alternative, less satisfactory solution. 


\section{Structural solution}

As already noted many subsidence claims relate to poorly constructed structures or differently founded sections of a structure. The result is differential movement. A solution for such situations should be a structural one and not tree removal.

There are situations too where tree removal is not a solution due to the possibility of heave. Large trees significantly predating and near a property — subject to species, damage history, soil conditions, structural type - may cause more or new damage to a property if removed.

\section{Perspective}

Average rainfall levels through the late 1980s and early 1990s were approximately $400 \mathrm{~mm}$, allowing for seasonal moisture deficits close to trees to recharge. Even in a dry year like 1989 the seasonal deficit of $250 \mathrm{~mm}$ was substantially less than the $400 \mathrm{~mm}$ annual rainfall.

In most subsidence cases, cracks open during summer and early autumn but re-close. Since subsidence became an insurable item in the early 1970s, however, seasonal movement became a major structural concern for house-owners. Consequently, there has been a cultural shift from one where seasonal movement and minor cracks was taken for granted to one where it is viewed with dread. It has engendered the idea that removing the inconvenience of wallpaper splitting every summer was more important than the existence of a 200-year-old oak tree.

\section{DISCUSSION}

Several years ago the Arboricultural Association attempted to establish a Subsidence Risk Factor (SRF) based on a significantly more detailed set of criteria than that used by the NHBC. It:

- categorised trees into six rather than three moisture demand categories;

- took account of actual plasticity rather than just a P.I. category;

- took account of a tree's crown shape rather than simply height;

- factored in climate differentials around the UK.

Despite this refinement 'considerable foundation movement has been shown to occur where the SRF indicated insignificant risk' (Biddle, 1998).

This suggests that the many other interrelated variables that have been touched on must be considered for each site. Thus if an 'apple tree' is observed we do not know what graft it is. If a pine is noted we do not know what species it is. We rarely know anything about the ground other than perhaps reference to a site being within a geological area identified by a 1:50,000 geological drift map (is it saturated, compacted, etc), do drains leak, is there a history of mining, do foundations depths vary, what, indeed, are the foundation depths, is there sufficient area to allow for natural recharge, have trees been removed in the past, where cracks are noted, are they actually as a result of desiccation shrinkage and so on.

Table 3: Structures that can be legally built without any professional involvement 


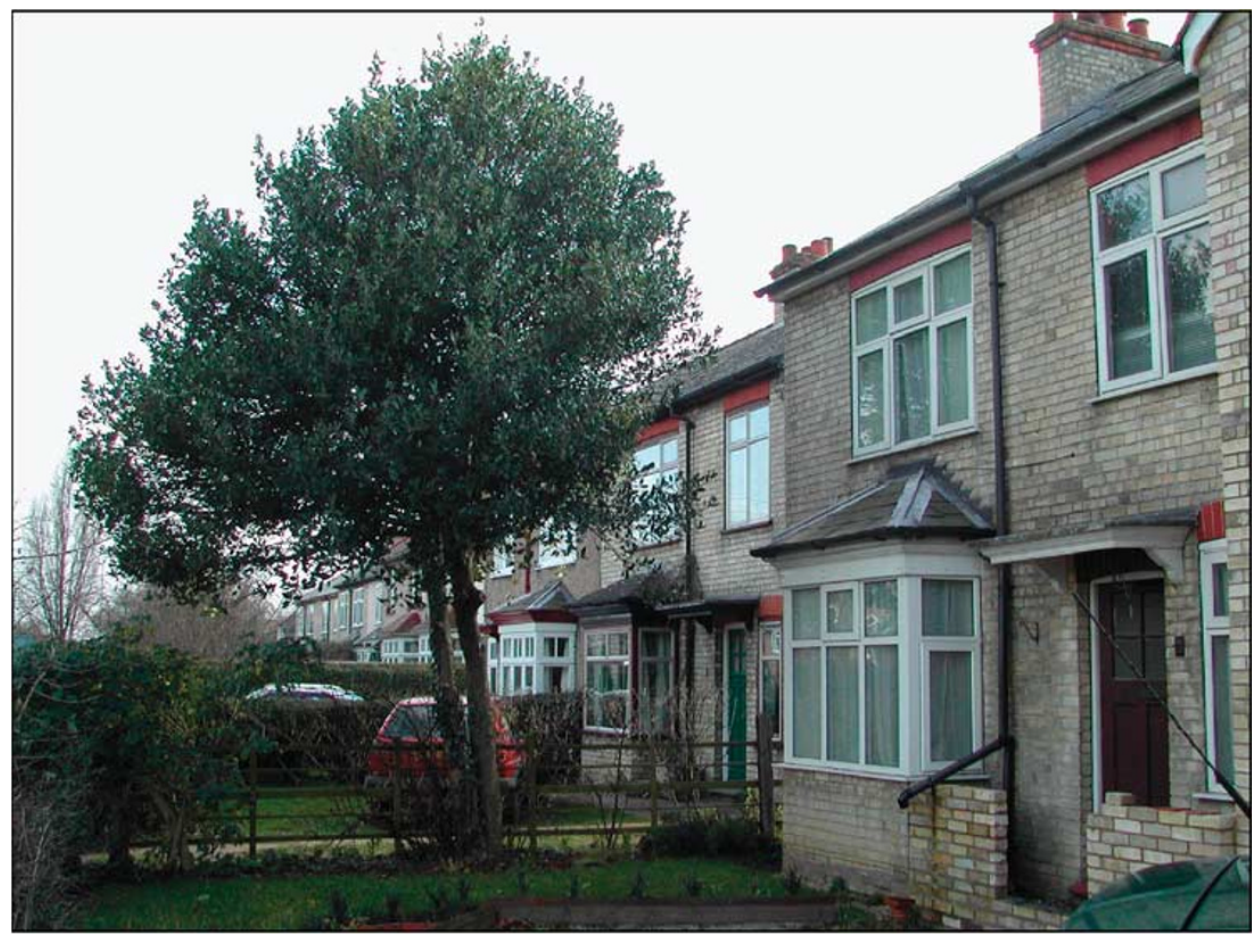

Figure 4: Illustration of how root spread may be influenced by ground conditions. Roots exploit anaerobic strata of soil at depth and extend within it before encountering high soil moisture levels adjacent leaking drains and proliferating

Professionals take an excessively cautious attitude in a litigious society. Figure 4 shows a 50-year-old holly tree $3 \mathrm{~m}$ from a house. It will not grow much larger, holly is slow growing, it is considered to have a low moisture abstraction capacity and the house is founded on a sandy, gravelly loam. This tree represents no threat at all to the property yet a surveyor advised removal. Basic criteria have not been applied let alone the detailed assessment of factors summarised in this paper.

Many of the claims or circumstances where damage has occurred and what much of the available data is based on relates to poorly constructed and founded structures, extensions, conservatories, bay windows and so on.

Perhaps we should be asking:

- How serious is the damage or is it merely inconvenient?

- Do some of these structures really warrant insurance cover?

- What is the cost of underpinning these structure or, frankly, re-building them?

If trees are considered to pose a threat or to have caused damage, more attention needs to be given to the implications of tree removal. At present decisions are based on a purely monetary one. A cost benefit analysis is applied whether it be to the cost of foundations, structural repair or tree removal. These are quantifiable items and, therefore, the decision is black and white.

The value of trees, however, is far more intangible. Their value includes their role in:

- moderating climates - particularly in urban environments;

- how they filter out significant proportions of atmospheric pollutants; 
- how they suppress noise such as traffic;

- how they provide a 'feel good factor' (studies have conclusively shown that patients convalescing in hospital, recover far more quickly in rooms overlooking mature trees than rooms overlooking the back of a building or car park);

- how they are a key source of shelter and food for wildlife and promote biodiversity;

- but finally, and perhaps most relevantly in this context, how mature trees increase the value of properties.

Although attempts have been made to value trees, I suspect this will remain elusive. One must try and consider whether $£ 2,000$ to underpin (or re-build) a conservatory is a more sensible option than $£ 900$ to remove a large tree and the possible consequential loss of value to the house (perhaps up to 20 per cent) and of all its benefits to the area.

\section{CONCLUSIONS}

Noting the presence of a tree(s) is necessary in any survey but this must always be accompanied with a clear statement that certain minimum criteria must be substantiated before implicating the tree(s).

The greater the information gathered the more reasoned a conclusion but foundation depths on all parts of the property, analysis of the founding soils and a survey from an arboriculturist (as opposed to a tree surgeon) must be established.

Where movement has occurred the cause of the movement must be determined beyond reasonable doubt and the above requirements in addition to level monitoring over a suitable period of time should be expected.

Although tree surgery and management has been increasingly rejected this should remain an option. There are many circumstances where it is effective but careful assessment of the site, distance, history (if any) of damage, species and how it will react to particular types of tree surgery must be undertaken.

In terms of the future, this writer would recommend certain new measures that, in the longer term, could greatly improve the likelihood of peaceful co-existence of tree and structure or remove the doubt that prevails. These include:

1. A new method of determining foundation depths for new build. Rather than following a set formula, penetrometers should be used for each site to determine at what depth the bulk density increases to the extent that root growth cannot or is unlikely to occur. If excessive, a raft should be constructed.

2. Planning legislation must be changed so that building control regulations are required for all brick/block built structures, regardless of size.

3. Some form of cost benefit analysis should be adopted that takes into consideration all the benefits that a tree or trees provide, the cost of structural repair or root barrier installation and the cost of tree surgery.

4. The insurance industry needs to evaluate properties (exempting houses built preNHBC guidelines) and how they have been constructed before providing subsidencerelated cover.

\section{References}

Biddle, P.G. (1998a) Tree Root Damage to Buildings. Volume 1 Causes, Diagnosis and Remedy, Willowmead Publishing Ltd., Wantage UK. 
Biddle, P.G. (1998b) Tree Root Damage to Buildings. Volume 2 Patterns of Soil Drying in Proximity to Trees on Clay Soils, Willowmead Publishing Ltd., Wantage UK.

Biddle, P.G. (1992) Patterns of Soil Drying and Moisture Deficit in the Vicinity of Trees on Clay Soils, DoE Research 1991-1992.

Binns, W.O. (1980) Trees and Water, Arboriculture Leaflet No. 6, Forestry Commission Research Station, Surrey, England, BRE Digest 240 (1993).

Coutts, M.P. (1979) ‘The physiological characteristics of trees and damage to buildings by root activity', Arboricultural Journal, 3(6), 413-419.

Crawford, R.M.M. (1974) 'Tree root survival under flooding, concrete, traffic and gas leakage', Paper presented at the 'Tree growth in the landscape' Conference, Wye College, April 1974.

Cutler, D.F. and Richardson, I.B.K. (1997) Tree Roots \& Buildings, Longman, Harlow, Essex.

Eschner, A.R. (1967) 'Interception and soil moisture distribution', in Sopper, W.E. and Lull, H.W. (eds) International Symposium on Forest Hydrology, Pergamon Press, London, pp. 191-200.

Ford, E.D. and Deans, J.D. (1978) 'The effects of canopy structure on stem flow', Journal of Applied Ecology, 15, 905-917.

Hunt, B., Walmsley, T.J. and Bradshaw, A.D. (1991) Importance of Soil Physical Conditions for Urban Tree Growth Forestry Commission Bulletin, 97 (Paper 8).

Koslowski, T.T. (1985) 'Soil aeration, flooding and tree growth', Journal of Arboriculture, 11(3), 85-96.

Ruark, G.A., Madder, D.L. and Tattar, T.A. (1982) 'Influences of soil compaction and aeration on the root growth and vigour of trees: a literature review’, Arboricultural Journal, 6, 251-265.

Watson, G.W. (1988) 'Organic mulch and grass competition influence on tree roots', The 2nd UK Conference of Urban Forestry, Morton Arboretum, June 1991. 